\title{
ENABLING PUBLIC SERVICE
}

\author{
JAMES CLOTFELTER*
}

\section{INTRODUCTION}

Almost everyone approves of the concept of volunteerism, at least in its unstipended form. The important questions are how do we make it meaningful for the volunteer; effective for society and the people being served; and affordable for society and the volunteer? The three articles discussed here address these questions, though none tries to answer all three. The first article focuses on a 1960s experiment in stipended service that tries to answer the "meaningful" question but not the other two. The second and third articles summarize what the authors know about the "effective" question, with some references to the other two questions. Together, they move us toward the point at which scholars can address all three questions.

KORSTAD AND LELOUDIS ARTICLE

Robert Korstad and James Leloudis in Citizen Soldiers in the War on Poverty have tackled a subject of considerable historical importance. ${ }^{1}$ The North Carolina Fund was an important social experiment, and we need to learn more about the Volunteers' experience, for the light it sheds on service-learning generally, as well as on the history of 1960s anti-poverty programs.

The North Carolina governor, Terry Sanford, was a nationally prominent supporter of creative approaches to social problems. He encouraged the Ford foundation to launch the Fund as an anti-poverty program. The Fund, a predecessor of Lyndon Johnson's Community Action agencies, had national as well

* Vice Chancellor for Information Technology and Planning, and Professor of Political Science, The University of North Carolina at Greensboro.

I should make clear that, regarding volunteerism, I am not a scholar, distinguished or otherwise. Let me note the experience I do bring, so my biases can be recognized. One of my responsibilities at The University of North Carolina at Greensboro is for University/community partnerships, and my work on one of those partnerships is relevant to the topic of this symposium. With the assistance of President William Friday and funding from Tom Lambeth of the Z. Smith Reynolds Foundation, Jim Van Hecke and I created the North Carolina Service Project. With the cooperation of the Center for Creative Leadership and schools and colleges across the state, we also created a "young service leaders" program. Shortly afterward, I worked with the faculty at UNC-Greensboro and Governor Hunt's new Smart Start program to create the North Carolina Child Care Corps, the largest full-time AmeriCorps program in North Carolina and one of the largest AmeriCorps programs in the United States focusing on early childhood development. Over the next three years, 100 young Corps members served in childcare centers in 15 North Carolina counties. My experience, then, is with what is usually called stipended service.

1. Robert A. Korstad \& James L. Leloudis, Citizen Soldiers in the War on Poverty, 62 Law \& Contemp. Probs. 177 (Autumn 1999). 
as state significance. Korstad and Leloudis, in this article and an earlier draft, make clear their enthusiasm for Governor Sanford's leadership and for the poverty-fighting potential of the Fund. Sometimes this enthusiasm threatens to overpower their scholarly intent. For example, they may overstate the backwardness of North Carolina, circa 1960, and thus dramatize the boldness of Sanford's contributions. The Fund was an important experiment, but, even if it had succeeded entirely, it would not have transformed the state.

The authors focus on the Fund's 1964 and 1965 summer programs which involved 350 volunteers. Scholarly study is aided by the presence of Fund Volunteers' daily logs and other records in the holdings of the Southern Historical Collection at the University of North Carolina at Chapel Hill. ${ }^{2}$

The Volunteers were recruited from North Carolina's college students, at a time when a much smaller percentage of North Carolinians of college age attended college. Consequently, the Volunteer pool was an educated, largely middle-class group. Yet, it was diverse for the time, with a significant minority of African-Americans. ${ }^{3}$ The values of the Fund Volunteers appear to have been "liberal" when they started, though perhaps not the same brand of liberalism with which they finished. Even in 1963-65, there was a modest tradition of biracialism and volunteer service on college campuses, most notably at UNCChapel Hill, that the Fund tapped into, rather than inventing.

The goals sought by the Fund are unclear, but creating only a "summer of service" seems designed to transform the Volunteers, and probably not the state. Yet transforming participants is an important part of any service-learning program. The quotations from the Volunteers' logs are immensely interesting and reveal that many of the Volunteers appear to have been deeply moved by their experiences.

In later studies, the authors could make some rich comparisons between the experience of the Fund Volunteers (and the Fund generally) and the experience of anti-poverty organizations in other states. Resistance from local officials in North Carolina was prevalent as it was elsewhere in the country in 1965-69. The post-1965 training of the Fund's "nonprofessional" Community Action Technicians might deserve an article of its own-again, with comparisons to the experiences associated nationwide with the "maximum feasible participation" mandate of the Community Action Programs.

The authors argue for looking beyond "direct service to poor communities" and for "power brokers in the public policy arena" to "confront and transform existing social and economic relations." They argue that the Fund's "mistake"

2. In the spirit of full disclosure, I was in North Carolina in the 1960 s, as a student, a participant in civil rights protest movements, and a newspaper reporter. I knew some of the people involved with the Sanford administration and the North Carolina Fund, and I admired them even if I did not always agree with them.

3. Creating a corps that is heterogeneous in terms of class remains, in 1999, one of the most difficult challenges. I know of few examples of successfully bonding corps members across class lines. We sought to do that with the North Carolina Child Care Corps, and it was one of our most difficult tasks.

4. Korstad \& Leloudis, supra note 1, at 195-96. 
was "in setting that goal against a sustained and robust program of student volunteerism. With the shutdown of the Volunteers program, the Fund lost much of its ability to build broad-based support for its work" by reducing the chances for "interracial, cross-class alliances." These assertions could be evaluated more easily if we knew more about the impact and the costs of the Fund's Volunteer program. Were there efforts to evaluate or even measure community impact? Perhaps we can conclude that the experience was transforming for the Volunteers, but was it transforming for the communities? If this program was to have been continued in the 1960s (or revived in the future), how much would it have cost? How much was spent on training? What was the staff/Volunteer ratio? What were the operating costs per Volunteer in the field? Could the Fund ever be the template for continuing organizations then or now?

In the end, the Korstad and Leloudis article leaves questions unanswered. The study is valuable in its own right, however, as an historical portrait of a major experiment and the lasting impact such experience has on the participants.

III

\section{GROSSMAN AND FURANO ARTICLE}

The second article-as does the one discussed in the next section-addresses unpaid volunteers, rather than stipended "national service" workers, and this distinction affects almost every feature of the participants' experience, the staffs' responsibility, and the programs' impact. Making this distinction is made more difficult because corps programs, such as the North Carolina Fund, often call stipended corps members "volunteers."

Jean Baldwin Grossman and Kathryn Furano, in Making the Most of Volunteers, seek to identify the elements that must be in place to allow volunteers to be effective. ${ }^{6}$ Some social problems are too complex or acute to be adequately addressed by volunteers at all, but, in those areas in which volunteers can succeed, the authors ask how success can be made more likely. They identify three areas as important: (1) screening; (2) training; and (3) ongoing management and support.

\section{A. Screening}

Agencies screen for the level of skills possessed by each applicant. The authors suggest that most programs choose a mixed strategy of screening for people who already have skills while recognizing they must devote time and resources to teaching volunteers needed skills.

Every agency knows that, if it has volunteers with high skill levels, those volunteers will perform at a higher level. For example, the Harvard student

5. Id. at 197.

6. See Jean Baldwin Grossman \& Kathryn Furano, Making the Most of Volunteers, 62 LAW \& CONTEMP. PROBS. 199 (Autumn 1999). 
body will perform certain academic tasks at a higher level than the student body of most community colleges, independent of anything done by the faculty and staff. The question here is what is the purpose of the volunteer service? If the purpose is to provide a high level of skilled service, it becomes a financial calculation whether that service can be best provided by a paid staff of a given size or by volunteers supported by a smaller staff. However, if part of the purpose is to transform the volunteers - to affect their lives-then you cannot limit recruitment to Harvard students. You must accept some volunteers without appropriate skills and train them.

This is not the same as screening for attitudes toward the work-will they be conscientious? - or doing background checks on applicants, both of which are appropriate for all organizations. Similarly, ensuring that volunteers understand the time commitment is essential. The authors note the significant range in time commitment required in volunteering. They present data on the dangers of having volunteers enter into a relationship with a "vulnerable individual," for example, a child while volunteering for Big Brothers or Big Sisters, and then fail to follow through. Indeed, the importance of relationships being long and full argues for full-time service instead of volunteers for some kinds of education and social service.

\section{B. Training and Skills}

The authors describe two types of training, content-focused and processfocused, suggesting that the latter receives too little attention. Any college professor who has supervised a student intern knows that one of the greatest challenges to a successful internship is navigating the organizational setting. The authors probably are correct in concluding that the same is true for agency volunteers. In the North Carolina Child Care Corps, we devoted a great deal of time to training. ${ }^{7}$ It was unsettling to realize that our Corps members, after one month of intensive training-leading to a community college Child Care Credential-had more formal training than fifty percent of the child care workers in North Carolina. ${ }^{8}$

\section{On-going Management and Support}

The authors' discussion of volunteer assignments and their examples are sensible. They also report on the importance of supervision for the success of volunteer mentors. This includes helping the volunteers deal with initial frustrations, ordering materials, and handling tasks requiring specialized knowledge. It would be interesting to see more data on costs. At what point does it make sense to hire more staff and rely less on volunteers? What is the cost in volunteer productivity of replacing staff support with non-staff support? Given the supervisors' frustrations, can a case be made for a high-cost, high-

7. Supra text accompanying note 3 .

8. S. Russell et Al. Working in Child CARE Centers in North CARolina (1993). 
productivity strategy? I understand there is a political dimension here that requires agencies to persuade someone to finance such a strategy.

I am interested in projects exploring ways to have stipended corps members supervise unpaid service providers. If this approach succeeds, it offers a less expensive approach than staff supervision, but it still requires good training and supervision for the stipended workers. If fifth graders can teach second graders to read, as occurs in the Israeli/UNC-Greensboro program Reading Together, then perhaps stipended workers can provide that guidance for volunteers.

The authors' discussion of the importance of internal communications, the agency "buying in" to what the volunteers will do, and continuing support from the agency all are sensible. The authors' discussion of the costs of infrastructure is welcome, though we need to include other administrative costs as well. We want to be able to calculate the total cost per hour served, or per task performed, and come to a judgment about the programmatic value of volunteers.

The Grossman and Furano article, like the Korstad and Leloudis study, does not include information about the impact of volunteers or corps members. To some degree, this is a problem of time. Many of the results of such service occur some time after the service has been performed. For example, an environmental project to reduce the damage from floods cannot be evaluated until some time after the environmental group has finished its work. Even when longer-term impact cannot be easily measured, however, some attempt should be made to measure the results of training and subsequent service. ${ }^{9}$

IV

\section{BRUDNEY ARTICLE}

Finally, Jeffrey Brudney's article, The Effective Use of Volunteers: Best Practices for the Public Sector, ${ }^{10}$ reviews the relevant literature and then uses what is described as a "marketing study" of volunteer programs housed in governmental agencies — as distinguished from non-profit agencies — to identify practices correlated to the programs' perceived success. Brudney's article is ambitious and contains much that is valuable in terms of descriptive data and suggestions for further research. Volunteer programs in the government and non-profit spheres will be organized and operated with or without good data on how to make them succeed. Brudney is correct that volunteer managers would benefit considerably from having the kind of data he hopes to develop.

The review of the literature is interesting, and extends far beyond what is needed to inform the research. The author identifies seventeen or eighteen "good practices" in volunteer administration. With the possible exception of

9. In the North Carolina Child Care Corps, for example, we videotaped a week's worth of interactions between Corps members and children at two points during their service, to determine if the Corps members were continuing to use what our trainers believed were developmentally appropriate teaching and discipline approaches.

10. See Jeffrey L. Brudney, The Effective Use of Volunteers: Best Practices for the Public Sector, 62 LAW \& CONTEMP. PROBS. 219 (Autumn 1999). 
annual evaluations for volunteers, all are practices that volunteer organizations would be likely to endorse in principle, if not in practice.

The author is gathering information in a complex area with considerable challenges in defining populations and behaviors. His "marketing study" is based on a sample of volunteer programs housed in government agencies across all levels of government. The sampling methodology is complex and multistaged. The method begins with identification of almost 5,000 volunteer programs through telephone calls and follows with a mail questionnaire sent to a sample of 500. In the end, the author collects 188 usable questionnaires. Unfortunately, as the author acknowledges, the sample is not representative of any population of government-based volunteer programs or program managers. Indeed, the author is straightforward in identifying several weaknesses in the sampling method. In the literature review, we learn that "the great preponderance of volunteers to government assist[] local governments." "11 Brudney points out that his sample contains more federal programs than is likely to be true of the total population of public volunteer programs, and provides an explanation. If federal programs are indeed early adopters of good practices, then that could be a reason for focusing on them.

Managers were asked whether their agency had listed "characteristics" of volunteer programs. The author seeks to correlate the presence of these characteristics to the benefits the volunteer coordinators perceive have come from the volunteer programs. Benefits are measured as the sum of the "yes' answers to eleven questions, admittedly an imprecise method of measurement. The more troubling problem is the one the author identifies: to the extent these questionnaires were filled out by people for whom volunteer coordination is a large part of their job, they presumably will have positive views of their volunteer programs. Both sides of the correlation involve the perceptions of the managers, so we are correlating a coordinator's perception of one thing with his or her perception of a different thing. Unsurprisingly, coordinators who devote more time to volunteer coordination, and have budgets devoted to that purpose, are more likely to believe their programs are successful.

Once the limitations of comparing perceptions are acknowledged, however, the study still provides a great deal of information about these programs' characteristics. The field is rich for further research with more focused samples and mixed objective and subjective measures of success.

11. Id. at 228 . 


\section{CONCLUSION}

All three articles address important subjects that need this attention, and more in the future.

Stipended service (as in the North Carolina Fund) has had difficulty gaining traction since the great successes of the Civilian Conservation Corps in the 1930s and the Peace Corps since the 1960s. Stipended service is costly in terms of time, money, and inspiration, and it is always freighted with great political significance by both friends and enemies. In the 1990s, AmeriCorps was so closely associated with President Clinton that voting to delete funds for AmeriCorps became a reflexive act of anti-Clintonism.

It is possible that service-learning, the collection of practices associated with stipended service and many college internships, may have considerable cumulative effect on how college students (and some high school students and graduates) volunteer. This may occur without the United States having a single, highprofile service-learning organization.

Non-stipended volunteerism, by contrast, has been seen as a non-partisan solution to many social problems. The number of people volunteering and the number of hours volunteered are staggeringly large. Here the challenge is to know what to make of something that everyone claims to favor-and most people claim to do.

Neither stipended service nor volunteerism can be defended successfully unless we are seeking a mix of societal benefits and benefits for the volunteer/corps member. Neither can be successful if we are not willing to provide the support the authors discuss in these articles. 